\title{
CUERPO: DE CARA A LAS POLÍTICAS COTIDIANAS DE LA APARIENCIA
}

\section{BODY - FACING DAILY DOCTRINES TO APPEARANCE}

John Jairo Uribe Sarmiento ${ }^{1}$

Jeimy Johana Acosta Fandiño ${ }^{2}$

Resumen

El presente artículo discute los procesos de construcción de subjetividad asociados al despliegue de las apariencias personales, así como de las tensiones que giran en torno de las categorizaciones que califican (o descalifican) a unos y a otros a partir de su vestir. El texto presenta los resultados de un proceso de investigación sobre el cuerpo, interrogando tales procesos desde la actual constitución del capitalismo.

Palabras clave: Subjetividad, poder, cuerpo, apariencia.

Abstract

This paper discusses the arrangement process of subjectivity associated to deployment of personal appearance, and tensions regarding categories used to qualify or not some people and others as from their own clothes. The content offers partial research results on body, questioning such processes from the existing creation of capitalism.

Keywords: Subjectivity, power, body, appearance.

Fecha de recepción: 31 de mayo de 2012

Fecha de aprobación: 18 de septiembre de 2012

\footnotetext{
1 Antropólogo, candidato a doctor en Estudios Políticos y Relaciones Internacionales. Docente e investigador de la Universidad de Ibagué, Programa de Ciencia Política. Correo electrónico: juandepatmos1972@yahoo.com.mx

2 Diseñadora industrial, Universidad Antonio Nariño. Correo electrónico: coorriente@yahoo.com
} 
Entrevistador: ¿A qué se refieren cuando dicen que una persona es "guisa"?

Mujer, 16 años: Más o menos hace referencia a las cocineras, normalmente uno intenta "pordebajear"2 a las personas, haciéndolas sentir muy inferiores a uno. Digamos, [tratándolas] como mesera o cocinera, que es algo muy inferior.

Mujer No. 2, 16 años: Pues, la verdad, yo creo que no utilizo esa palabra. Pero creo que es algo, como dice ella, para "pordebajear" a una persona que se ve diferente, que no es igual a uno, que tal vez ella se ve bien pero a uno le parece que se ve mal, entonces le dicen "guisa", le dicen que se ve mal, que se ve sucia, eso significa guisa.

\section{Presentación}

La pregunta por el cuerpo no se refiere a lo que este es, sino a lo que puede hacer: qué puede decir, qué exhibir, qué comer, de qué modo puede comportarse, de qué forma cuidarse. En este universo de lo posible, en su estructuración, se juegan diversas fuerzas y tensiones que pasan por el empleo de términos que categorizan, diferenciando a unos y a otros de acuerdo con ciertos atributos: no cumplirlos pone de manifiesto cierta carencia que se paga con el descrédito, "convirtiéndose" en "guisa", o en otros epítetos de esta sazón.

Así que los ropajes no solo expresan búsquedas personales de expresión, sino que se hacen signo de señalamientos, insultos, fragmentaciones y luchas complejas. En otro nivel, este tipo de aproximaciones se refiere a la lógica que ha producido sujetos afanados por su apariencia, por su diferencia: a qué tipo de sociedad corresponden estas preocupaciones por la moda, por el porte, por la correspondencia entre la ropa, los ademanes, en fin, por la verdadera identidad de cada quien. El presente artículo recoge algunos de los resultados del proyecto de investigación Representaciones sociales e imaginarios corporales en estudiantes de 4 y 5 ciclo, desarrollado desde el Instituto para la Investigación y el Desarrollo Educativo -IDEP-. En este proyecto se abordaron tres categorías claves: las apariencias, el cuidado de sí y las afectividades. Aquí se avanzará en una discusión sobre la relación entre estética, poder y resistencia, poniendo el acento sobre las lógicas de producción de las subjetividades a través del modo

1 Guisa es sinónimo de sirvienta. Se asocia también con el guiso de cocina, con su olor y con el trabajo de cocina.

2 Colocar por debajo, en el sentido de insultar y de referirse a otro como una persona "inferior" social y moralmente. como los ropajes contribuyen a las construcciones sociales de las corporalidades.

Conviene recordar que estas cuestiones no son de poca monta, en tanto se refieren a un aspecto central de la reproducción del capitalismo contemporáneo: se trata del modo como este produce la materia prima necesaria para su supervivencia, esto es, las subjetividades encarnadas ${ }^{3}$. Las modas y por tanto las formas como se modela el "buen" y el "mal gusto", no pueden entenderse como asuntos meramente individuales, o puramente frívolos, sino que remiten a las dinámicas que pretenden dar forma al cuerpo, a sus volúmenes, a sus sensibilidades, a sus modos de hacerse visible. Pero ese "formarse corporal", es al mismo tiempo un esfuerzo por posibilitarse, es decir, por crear, administrar y gestionar las opciones humanas.

Entonces, la gestión de lo posible atraviesa al cuerpo. Ahora bien, esa gestión no alude a las meras capacidades musculares o cinéticas atribuidas a los diferentes cuerpos (de mujeres, de niños, de niñas, de ancianos, etc.) a través de la historia, sino que implica cuestiones éticas y políticas para nada despreciables: lo que el cuerpo puede hacer así como lo que no, es expresión encarnada de jerarquías sociales, de modos de explotación y de segregación, pero también de búsqueda, de invención y de resistencia. La tensión entre "el poder hacer" del cuerpo y "el deber" de su ser, se dibuja también por sus superficies, se intercepta y, algunas veces, se hace lucha; otras más, colaboración. El siguiente artículo presta atención a este universo de tensiones y complicidades.

A través del documento se presentan dos tipos de conflicto asociados a las apariencias: los que corresponden

3 Coincidimos aquí con la expresión de Guattari y Ronik en Micropolíticas del deseo. Para estos autores, la materia prima de cualquier tipo de producción se refiere a las subjetividades. Así pues, el capitalismo requiere de ciertas subjetividades, de ciertos modos de semiotizar la cotidianidad. De ahí que despliegue diversos procesos para proveerse de ellas. Vale decir que esa semiotización se refiere al modo como se designa la diferencia; por ejemplo, al modo como se establecen los diversos "tipos" de personas que "aparecen" en las relaciones cotidianas, así como a los significados que se les atribuyen, las expectativas que generan y los atributos que poseen. Por ejemplo, los "pobres" no se definen solo por su nivel de ingresos, sino que, al nombrarlos, se les atribuyen una serie de características que no aluden únicamente a lo que supuestamente "son", sino, sobre todo, a lo que "deberían ser", incluso en la literatura especializada. 
a las expectativas y los que emergen de los atributos. Los primeros se refieren a problemas que operan en razón a la coincidencia o no de lo que se espera de una persona y lo que comunica a través de su apariencia: se trata de conflictos relacionales. Los segundos se refieren a las tensiones que se generan para los sujetos mismos esos atributos que les son atribuidos: podrían denominarse como conflictos identitarios, o de la relación que cada quien establece consigo mismo.

El artículo pretende presentar en forma sintética los modos como los sujetos construyen esas experiencias que se han ubicado alrededor de las apariencias, de sus conflictos y de las lógicas cognitivas y estéticas que se ponen en juego. Como se ha mencionado, se ha hecho un esfuerzo por abordar a los hombres y mujeres jóvenes de los ciclos cuarto y quinto y para ello se apeló al desarrollo de talleres que a partir de ejercicios teatrales (de representación de la vida cotidiana en el colegio) les permitieran hablar del tema. Estas "conversaciones" se grabaron y se analizaron a partir de las tensiones inicialmente planteadas (expectativas y atributos). El abordaje de cada una de las categorías teóricas iniciales, se desplegó como un esfuerzo por entender los puntos claves que los hombres y mujeres jóvenes proponían; es decir, frente a las dos categorías de expectativas y atributos, se procedió a abordar la dinámica propia de las expresiones que los mismos jóvenes plantearon. La descripción que a continuación se presenta se desarrolla en el vaivén entre los referentes teóricos y los hallazgos empíricos. Por otro lado, se avanzó en desarrollar un esfuerzo interpretativo, esto es, en tensionar tanto las premisas expresadas por los jóvenes como las provistas por diversos abordajes teóricos asumidos, en relación con la reproducción del capitalismo contemporáneo.

La investigación pretende menos definir relaciones entre variables, o describir el comportamiento de ciertas categorías, que problematizar el modo como unos y otras construyen su propio cuerpo en relación con el modo como se visten y como juzgan a los demás por su apariencia, preguntando si esos modos y juicios se corresponden o no con otras dinámicas. Aún cuando la investigación define y desarrolla criterios de rigor (tomar en serio las construcciones de los jóvenes, poner en cuestión los preceptos culturales de los investigadores), su aporte gira en torno de las problematizaciones que el material obtenido permite hacer en relación con el mundo contemporáneo.
En primer lugar se presentarán las tensiones referidas a las expectativas, luego se plantearán algunas consideraciones conceptuales en relación con el papel del cuerpo en el desarrollo de relaciones de poder y finalmente se discutirán las tensiones referidas a los atributos.

\section{Las pintas no son lo de menos}

En primer lugar, el cuerpo no se entiende como un lienzo, como un objeto pasivo que "recibe" una forma cultural. No se trata de una "interfaz" que articula lo material con lo inmaterial, una bisagra que conecta las ideas con la acción. No se trata de un cuerpo-objeto que recibe significados predeterminados. El cuerpo, más que un receptor, es una forma compuesta por, y formadora de, relaciones de fuerza. Se trata de lo que SánchezCriado (2008) denomina como heterogénesis y ecologías en la construcción mutua del cuerpo. Aquí la cuestión no es qué es el cuerpo (como una cosa definible), sino qué puede hacer este, cuestión esta que termina siendo la pregunta por cómo se vincula el cuerpo: las posibilidades corporales se constituyen por las redes de vínculos en las que participa, lo que coloca a la apariencia en un lugar clave para comprender las relaciones de fuerza y sus dinámicas vinculantes.

El análisis del cuerpo es el de sus prácticas, entendidas como mediaciones, como potencialidades, como posibilidades que se originan en los vínculos: "Dicho en positivo cómo se vincula y con qué se vincula un cuerpo definen lo que es un cuerpo" (Sánchez-Criado, 2008 p. 287). Se trata de un cuerpo en (y de) la práctica y la acción. Práctica clave, la de aparecer ante los demás:

Entrevistador: ¿Qué da esa apariencia de guiso? Mujer, 16 años: Por su apariencia, son las típicas niñas que [van] con sus ombligueras, como que [van] megaentubadas ${ }^{4}$, que resultan como salchichas rellenas ${ }^{5} . \mathrm{Su}$ maquillaje es sucio, ¿si me entiende?, como muy loba ${ }^{6}$.

Se nota en sus peinados que son como si tuviera una miscelánea en la cabeza, llena de hebillas, de moñas, de todo.

Mujer No. 2, 16 años: Y el hablado.

4 La expresión "entubado" se refiere al ajuste de los pantalones en las piernas. Aquí se usa en forma ampliada para referirse a la ropa ajustada.

5 Se trata de alguien que se ve mal con ropa ajustada, pues se ve "apretada".

6 Se refiere, como una prostituta, en todo caso, alguien que exagera su maquillaje para llamar la atención. 
Mujer, 16 años: También la forma en que se expresan.

Entrevistador: ¿Si? ¿La forma de expresarse? ¿Cómo es un hablado "guiso"?

Mujer, 16 años: Cuando gritan, nada más uno grita, $y$ ya, eso es, eres una guisa ¿ya? Que comienza a hacer bulla, eso es, como bandera ${ }^{7}$ ¿sí?

Mujer No. 2, 16 años: Se expresa muy vulgarmente hacia otra persona, no puede hablar en forma decente, sino gritando, diciendo groserías, insultando de una vez. Así sea entre amigos, pero va hablando así.

Como se lee, la "guisa" es una mujer ordinaria a la que se le atribuyen características inmorales, es una loba (mantiene relaciones sexuales con muchos compañeros) y es grosera. Las apariencias se juegan en el terreno de los supuestos, de lo que en el lenguaje cotidiano se "supone" que debe hacer una "señorita" o un "joven". Lo que se puede esperar de alguien vestido con corbata difiere de lo que se esperaría de alguien en pantaloneta. De otro lado, el atuendo y la situación deberían coincidir: ¿esa corbata es adecuada para la cena de gala? ¿Tal pantaloneta es la correcta para el juego? Esos supuestos son formulados según lógicas sociales que operan en los terrenos de lo implícito:

La sociedad establece los medios para categorizar a las personas y el complemento de atributos que se perciben como corrientes y naturales en los miembros de cada una de esas categorías. El medio social establece las categorías de personas que en él se pueden encontrar (...) Por consiguiente, es probable que al encontrarnos frente a un extraño las primeras apariencias nos permitan prever en qué categoría se halla y cuáles son sus atributos, es decir, su identidad social (...) Apoyándonos en estas anticipaciones, las transformamos en expectativas normativas, en demandas rigurosamente presentadas. (Goffman, 2008 pp. 13-14)

Vale la pena destacar de esta aproximación dos aspectos claves. Primero: las categorizaciones generan expectativas, esto quiere decir que, de un cierto tipo de personas, se espera un comportamiento más o menos específico. Goffman denomina a estas expectativas identidad social virtual, aludiendo a que se trata de categorizaciones que operan de forma esencialista, esto es, cada categoría implica una "esencia" que define a todos los que a ella pertenecen y lo que puede esperarse de ellos, sin que exista una argumentación explícita.

7 La expresión bandera se refiere a alguien que llama la atención, que es "colorida", llamativa, expresiva.
Segundo: a cada categoría corresponden ciertos atributos. A estos Goffman los denomina identidad social real. Tenemos entonces, de un lado, las expectativas $y$, del otro, los atributos, todo ello operando en el terreno de los supuestos. De la coincidencia entre aquello que se atribuye a una categoría (el comportamiento esperado) y aquello que efectivamente se observa, depende que unos y otros se sientan cómodos o que se construyan estigmas, señalamientos que pueden llevar a la exclusión y al castigo social:

Por lo general, parece cierto que los miembros de una categoría social sustentan sólidamente un modelo de opinión que, según su parecer y el de otros sujetos, no les es directamente aplicable. Así, un hombre de negocios puede exigir una conducta femenina de las mujeres o una conducta ascética de los monjes y no concebirse a sí mismo como alguien que debe llevar a cabo estos estilos de conducta. La diferencia está entre llevar a cabo una norma y simplemente sustentarla. El problema del estigma no surge aquí sino tan solo donde existe una expectativa difundida de que quienes pertenecen a una categoría dada deben no solo apoyar una norma particular sino también llevarla a cabo. (Goffman, 2008 p. 19)

Las apariencias, entendidas desde esta perspectiva, implican una dinámica de adecuación entre las características de alguien y las expectativas propias de cada categoría, con lo que está en juego, además, la "estima", la posición social, la "aceptación" o el "rechazo". La categoría "guisa" se aplica como estigma a las mujeres que no corresponden a un modelo claro de la feminidad: si se las considera agresivas sexualmente, que se visten de forma insinuante y que asumen comportamientos fuertes, o se visten en forma "popular" (con moñitas y hebillas en el cabello, por ejemplo), entonces ponen en cuestión la categoría que con tanto cuidado asumen las demás mujeres. Las apariencias comportan, entonces, costos y beneficios (para usar un lenguaje conductistaeconomicista) para las personas y los grupos, con lo que se entra de lleno en el terreno del cuerpo y de lo corporal, pues se trata de luchas en torno de cómo se lee el cuerpo, de qué tipo de lecturas se espera provocar y de qué tipo de reacciones se desea disfrutar. Pero ¿a qué nos referimos con la expresión "cómo se lee el cuerpo"? Pues precisamente a esa capacidad para identificar los símbolos que asocian a una persona con una cierta categoría y por tanto con su papel esperado y sus atributos. El siguiente testimonio (obtenido a través del proceso de investigación que se lleva a cabo desde la Universidad Pedagógica Nacional) puede ejemplifi- 
car lo que se pretende decir respecto de la apariencia y del cuerpo. Se trata de una entrevista realizada a una docente de 25 años que trabaja en el área de lenguas modernas en un colegio masculino y que recuerda algunas de sus experiencias en el instituto femenino donde cursó su bachillerato.

Mujer, 25 años: El temor de muchas niñas, en un femenino, a correr, era porque estábamos desarrollándonos, entonces nos daba pena pues... Entrevistador: De exponerse a la mirada... Mujer, 25 años: Sí claro, el cuerpito, la mirada, entonces que no se podía [correr] con saco, sino solo con camiseta, pantaloneta, entonces era la pelea [porque] nosotras no queríamos mostrar las piernas, no queríamos mostrar el busto, entonces nos obligaban prácticamente a utilizar camiseta y pantaloneta hasta que hubo cierta revolución. Revolución no quiere decir anarquía [...] revolución quiere decir expresar con argumentación frente a lo que le digan a uno. [Les decíamos a los profesores]: "Mira es por esto y esto, hay algo que se llama integridad y hay algo que se llama temor, pudor, entonces queremos que lo respeten". Se pudo lograr algo, pero en fin, es igual. Entrevistador: ¿[Ese temor, ese pudor] era ante sus propias compañeras o era porque había un posible público masculino viendo, por ejemplo el profesor? Mujer, 25 años: Pues el profesor, [lo que pasaba con el profesor] de educación física [era] que muchas niñas se sentían atraídas por él, [por la necesidad de] escape [que se vivía en el colegio]. No sé qué le veían pero se sentían atraídas por él. Pero entonces era también el pudor de no mostrarse a la compañera. Muchas veces, hablémoslo abiertamente, el temor a que se empezaran a sentir atraídas por uno también [era lo que nos preocupaba]

Destaquemos que no se trata de negociar el modo como se leen los cuerpos, esto es, de cuestionar los "deseos" que ellas provocaban, sino de confrontar la forma como estos se exhibían, esto es, de evitar que se produjera cierta lectura de su apariencia, al parecer, inevitable.

En síntesis, la apariencia implica el modo como se despliegan supuestos, articulando categorías (constituidas por expectativas y atributos) y generando dinámicas de conflicto que operan en, por, y a través del cuerpo.

Existen entonces dos tipos de conflictos en este nivel relacional: los referidos a las expectativas y aquellos que se articulan en torno de los atributos. Los primeros se desarrollan desde la inadecuación de ciertos tipos de personas frente las apariencias y comportamientos esperados. El apelativo "guiso", así como los de "ñero" y "farandulero" (como se ampliará más adelante), se refieren a este tipo de conflictividad. Más o menos intensa en los espacios escolares indagados, una primera mirada conduce a plantear que no es despreciable: expresa fenómenos de exclusión. Los conflictos asociados a los atributos (como relación consigo mismo, como tensión de tipo identitario) se analizarán más adelante en relación con la cuestión del estilo, del modo de hacerse "aceptable".

Entrevistador: ¿Qué es lo opuesto a guiso? Hombre, 16 años: Una persona decente. Mujer, 16 años: Un gomelo. Mujer No. 2, 16 años: No un gomelo precisamente, sino una persona que se sepa expresar, que sepa hablar, que se vista bien, que sepa moderarse, que sepa caminar, que haga todo eso. Entrevistador: Es decir, hay que aprender a caminar, a hablar, a modelar, pero ustedes piden mucho ¿no? Mujer, 16 años: No, o sea es la forma de ser.

Mujer No. 2, 16 años: Hay que ser damas, siempre. Saberse comportar ante la gente. Saber actuar ante la gente. Mujer, 16 años: Exacto, hay personas con las que digamos uno puede hablar de otra manera, hay personas con las que hay que comportarse, personas con las que hay que hablar bien. [Con ellas] no puede uno tomar un lenguaje vulgar para dirigirse, digamos para conseguir un trabajo, o sea, ;cómo se va a dirigir uno a su próximo jefe, todo vulgar y decirle: ah, es que entonces no me va a dar [el trabajo] o qué!

Entrevistador: Pero, ¿guisa es para mujer, no? ¿Hay guisos también? Hombre, 16 años: Ñero. Mujer, 16 años: Ñero, o guiso, igual.

Entonces, al guiso y al ñero se le opone la categoría de "decente", quien viste bien, habla bien y se mueve bien. Es, claro, muy difícil poner en palabras ese actuar bien, pero una de las acepciones encontradas en los talleres se refiere al modo de llevar la moda: si alguien usa los zapatos de moda, pero no los sabe combinar con el resto del vestuario, caerá en la categoría de "ficticio", de "ficti".

No es fácil definir qué tantos esfuerzos hacen los jóvenes para evadir las categorías denigrantes o en emplearlas para definir a otros, puesto que no las em- 
plean solo para definir conflictos relacionados con la apariencia, sino que terminan articuladas con otras dinámicas de control y de tensión. De hecho no puede decirse que este tipo de preocupaciones sea propia de esta edad o de esta condición sociocultural, pues otras edades y otras categorías sociales también enfrentan este tipo de problemas. Sin embargo, un indicativo de la importancia de estos asuntos para algunas mujeres jóvenes participantes del proceso de investigación, se refiere al esfuerzo por ser diferentes:

Entrevistador: Pero, ¿por qué es importante ser diferente?

Mujer No. 2, 16 años: Yo pienso que es muy importante sobresalir ante algo, no como lo decía ahorita, no en una forma ridícula ni nada de esto, sino por otras cosas, digamos, como ser inteligente, como saber expresarse ante la gente, yo creo que para casi todas las niñas es importante también sobresalir por su apariencia física, muchas intentan tener un estilo, obviamente todas las niñas tenemos un estilo diferente, por ejemplo a mí me gusta estar como siempre, linda, como muy princesita

Entrevistador: $Y$ si tuvieras que resumir tu estilo en una palabra ¿cuál sería? ¿Princesita?

Mujer No. 2, 16 años: No. Me refería a princesita pues porque ya normalmente ninguna niña quiere sobresalir de esa manera. Cuando ya todo el mundo se dispersa con su estilo, que dicen "yo voy para allá" o "yo voy para acá", o "yo voy por ese otro lado", somos muy pocos los que quedamos en el centro. Yo me considero que soy una persona normal, esto, somos muy pocos los que quedamos con estilo normal.

Entrevistador: ¿Cómo es el estilo normal? Mujer No. 2, 16 años: Pues en mi caso me gusta siempre verme elegante, formal, presentada, así esté en miércoles y esté lloviendo, no me importa, siempre verme presentada y que si llega no sé quien, alguien importante, pues no diga: " $i A y$ ! no, esta niña se ve mal". No, siempre estar presentada, por ejemplo a mí me molestan porque me maquillo ¿sí? Dicen: "Tan joven para maquillarse". Pero no es que me vea redundante [exagerada] ¿sí?, que me desfase en maquillaje. No, normal, siempre es estar bien presentado y ya. Y ya uno sobresale porque ya no hay tantos como uno, ya no hay tanta gente así, pues a mí me gusta lo femenino, me gusta verme linda, siempre

muy damita. Y no es que yo discrimine, simplemente no me gustan los tenis gruesos, eso no me gusta en una mujer, entonces en ese sentido uno sobre sale siempre por eso.
Como se acaba de leer, la cuestión del estilo (elemento identitario por excelencia) se refiere a la construcción de un relato de sí, se refiere tanto a los modos de evitar caer en las categorías que estigmatizan y condenan, como de presentarse de modo aceptable para sí mismo. Esas tensiones obedecen a lo que hemos denominado como atributos. Más adelante se ampliará este tema.

Ahora bien, estas dos series de conflicto (expectativas y atributos) aluden a diferentes dimensiones de las múltiples prácticas corporales asociadas a la presencia, al modo de "hacerse presente" ante los demás, un modo que se encuentra fuertemente asociado a las construcciones identitarias, a las formas de autodefinirse. Pero se requiere de un esfuerzo por ampliar la perspectiva para colocar estas observaciones en un contexto adecuado: en primer lugar, una discusión sobre los alcances del poder entendido como modulación y por último, la pertinencia epistemológica, ética y política de las apariencias para abordar la compresión de las formaciones sociales contemporáneas.

\section{Entre los poderes, las resistencias y las estéticas}

Maffesoli (2007) define la estética como un sentir juntos. De ahí que la ética y la estética se entrelacen, en tanto ambas se juegan en el modo como unos y otros definen aquello que los acerca y/o distancia. Lugar fundamental de esta estética-ética es la apariencia, esto es, los modos de aparecer, de formar cuerpo social desde la corporalidad personal. Aquí resulta necesaria una distinción clave: individuo y persona no coinciden. Conviene recordar que persona significa máscara, esto es, una construcción social que implica una dimensión relacional fundamental: la máscara alude al rol, al papel predefinido. Los individuos construyen relaciones complejas respecto a ese papel, algunas veces lo desarrollan, otras lo ponen en cuestión, otras lo ignoran, pero todo ello depende de las condiciones del escenario: si este es severo y restrictivo, esa suspensión del papel, ese desenmascaramiento, usualmente es castigado y reprimido.

Ahora bien, este carácter relacional de la estética y su traducción en la apariencia como máscara, se encuentra asociada a un efecto de velo. Este muestra y oculta a la vez. Esta capacidad del velo pone en duda la eficacia de la sociedad disciplinaria (la que pretende moldear el cuerpo de acuerdo a ciertos cánones) que apela al panóptico, a los aparatos de vigilancia que observan, clasifican y configuran las fuerzas corporales de acuerdo a objetivos predeterminados. Si para el panóptico es 
indispensable que la observación de-vele lo observado, las actuales dinámicas de microorganización social en formas de atracción y repulsión efímeras se desarrollan bajo lógicas veladas, cifradas, en las que los integrantes de cada grupo ocultan para sí sus modos de ser, mientras que exhiben ante otros señales destinadas a establecer su identidad, esto es, para establecer, a partir de allí, relaciones complejas de lucha, cooperación, negociación y/o complicidad. Para decirlo de forma un poco esquemática, el panóptico alude a la vigilancia y para ello requiere de cierta transparencia, que lo observado remita a categorías relativamente claras ${ }^{8}$. Las máscaras enrarecen esa observación y se acomodan más a otras dinámicas de poder y de resistencia.

Este llamado a la estética y a los modos de cohesión social que ella suscita, alude, por esta vía, a cierta dinámica de relación entre poderes y resistencias que vale la pena referir en relación con los resultados presentados hasta ahora.

La regulación de lo posible, tan cara a la construcción del cuerpo, es una tarea constante de las dinámicas culturales y de poder. Foucault (2006a) lo advierte en Seguridad, territorio y nación. Para él los dispositivos de seguridad se caracterizan por ubicar en un territorio las series de acontecimientos posibles. Esas series son definidas y administradas a través de la planeación, de la anticipación, del esfuerzo por contener lo imprevisible, esto es, poder de la seguridad. Se trata de la creación de un medio, de un lugar donde el cálculo de las probabilidades toma la batuta y se convierte en mecanismo de administración.

En este sentido, vale decir que Foucault (2006a, 2006b) define el poder como acción sobre acciones posibles, como esa capacidad para orientar las conductas posibles de los demás:

Lo que define una relación de poder es un modo de acción que no actúa directa e inmediatamente sobre otros. En cambio actúa sobre sus acciones: una acción sobre una acción, sobre acciones existentes o sobre aquellas que pueden surgir en el presente o en el futuro. (Foucault, 1991p. 84)

Foucault distingue entre el uso de la violencia, la obtención de consenso y el poder. Este último puede

8 Como se sabe, esta claridad no ha sido nunca completa, pues los sujetos catalogados construyen para sí espacios propios en los que confrontan, de forma oculta, los efectos de poder que viven. emplear a los dos primeros, pero, insiste, ni el uno ni el otro se confunde con él, pues la violencia y el consenso actúan directamente sobre los sujetos, mientras que el poder actúa solo en sus posibilidades de acción. En esta perspectiva, Foucault entiende el poder como ejercicio de gobierno; en un amplio sentido, como guía de conducta:

Gobernar en este sentido, es estructurar el posible campo de acción de otros. La relación propia del poder no debería por lo tanto buscarse del lado de la violencia o de la lucha, ni tampoco de la unión voluntaria (pues, a lo más, en el mejor de los casos, son sólo instrumentos del poder), sino más bien en el área del modo singular de acción (ni lo belicoso, ni lo jurídico) que es el gobierno. (Foucault, 1991p. 86)

Ahora bien, dado que se trata de sujetos actuantes, no está de más plantear que se trata de sujetos que cuentan con posibilidades de acción (lo que implica contar con recursos para ella), hecho que remite a la cuestión de la libertad. De ahí que las relaciones de poder/resistencia no sean necesariamente opuestas entre sí. Desde esta perspectiva, libertad y poder no se oponen, sino que se relacionan en forma compleja, es decir, se incitan mutuamente, aun cuando no se determinen entre sí.

El poder se ejerce sólo entre sujetos libres, y solamente en la medida en que ellos son libres. Con esto queremos decir, sujetos individuales o colectivos que están enfrentados con un campo de posibilidades en el que puedan realizar diversas formas de conducirse, diversas reacciones y diversos comportamientos. Donde los factores determinantes saturan el todo, no existe relación de poder (...) Por consiguiente no hay una confrontación cara a cara entre el poder y la libertad que sea mutuamente excluyente (la libertad desaparece donde se ejerce poder) sino una influencia recíproca mucho más complicada. En este juego la libertad puede muy bien aparecer como la condición para el ejercicio del poder. (Foucault, 1991 p. 87)

De ahí que no puedan existir relaciones de poder si, al mismo tiempo, desapareciese la posibilidad de desobedecerlas, de rechazarlas, de ponerlas en duda. Esta perspectiva ha llevado a Esposito (2006) a plantear que las relaciones de poder implican la producción ${ }^{9}$

9 Aquí se opone la producción del sujeto a la noción de que este es dado. Esta última noción -la de un sujeto dado- implica que el sujeto cuenta con unas características ahistóricas; 
de sujetos libres. En el mundo contemporáneo ha ocurrido una potenciación mutua del sujeto y del poder. Del primero como objeto de su propia sumisión. Del segundo, potenciando lo que somete, es decir que para que se ejerza eficientemente, el poder se ha esforzado por potenciar al sujeto al que solicita sumisión.

En efecto, al tratar de dar cuenta de "nosotros", de describirnos, de abordar nuestras motivaciones, debemos recurrir a términos que no hemos inventado, que en cierto sentido no nos pertenecen, debemos acogernos a una interpelación. Esos términos a los cuales apelamos para describimos son, no obstante, aplicables a cualquiera y hacen que el sujeto hablante sea sustituible ${ }^{10}$ y que su experiencia sea a la vez comunicable e incomunicable. Comunicable en tanto remite a un medio común y a unas posibilidades comunes (las del lenguaje); incomunicable, pues las experiencias desbordan las posibilidades del lenguaje (lo que genera un vacío). En consecuencia, para hablar de sí mismo, el sujeto se encuentra desposeído, pues en su propia constitución queda atrapado en el Otro, en el lenguaje y en la norma social a través de las cuales solo podrá brindar una imagen aproximada de lo que le ocurre (Butler, 2009).

Las tensiones derivadas del estilo, de esa narrativa que haga del sujeto tanto aceptable para los demás, como aceptable para sí mismo, se refieren a ese universo de constitución de sí mismo en la norma social. Si es importante hacerse a una imagen propia, casi original, esta imagen debe ser lo suficientemente llamativa como para hacerse notar, pero también lo suficientemente discreta para no rayar en la agresividad. Así, por ejemplo, en el eje de los conflictos sobre las expectativas, la categoría ficticio nos ofrece un lugar de lectura importante:

Entrevistador: ¿Ficticio? ¿Qué es ficticio? Mujer, 16 años: Quiere mostrar más... Mujer No. 2, 16 años: Que tiene que sobresalir para que la gente lo vea, tiene que hacer cosas absurdas para

por ejemplo, las condiciones psicológicas innatas, condiciones que cada cultura llenará de contenido a través del proceso de socialización. Foucault (1991), Guattari y Rolnik (2006) y Deleuze y Guattari (2003) coinciden en este punto: el sujeto en tanto que es producido, supone la generación de todas las características y no el aprovechamiento de algunas predeterminadas.

10 Sustituible porque al decir "yo", en un nivel del lenguaje, este se referirá a aquel que habla, pero en otro nivel ese "yo" se refiere a cualquiera. Con lo que mi historia es a la vez mía $\mathrm{y}$ de cualquier otro que desee usarla. que uno diga: "Ah, mire, allá está tal persona". Tiene que comportarse de una manera que uno dice: "Pero, por qué te comportas de esa forma si ya tienes una edad, o sea, yo sé que la edad no hace la madurez, pero si ya tienes por ahí 16 años, tienes que tener claro qué quieres, cómo quieres que te vean, cómo quieres actuar en la vida, pero si te pones a gritar, si te pones a saltar para que te vean eso ya es una persona muy ficticia". Hombre, 16 años: Por ejemplo yo le digo ficticio a una persona que aparenta que ha vivido muchas cosas, que ha hecho y ha deshecho y que tal, y a la hora del veinte ${ }^{11}$ uno se pone a hablar con ellos y les pregunta uno de esas cosas y se da cuenta que inventan. Por ejemplo, yo me he puesto a hablar con mucha gente de experiencias que he vivido y la gente "ah, yo también y tal", o dicen "es que yo también he hecho esas cosas y tal". Yyo: "si parce ${ }^{12}$, entonces, usted ¿cómo hace? Y tal y tal". Uno los escucha "Ah sí, parcero, bueno sí". Listo. Pero es que no saben lo que hablan, no saben qué es en realidad eso, entonces es ficticio.

El ficticio, aquel que aparenta, no solo se reconoce por cómo habla, sino por el modo de llevar su ropa y sus accesorios: su modo de estar a la moda devela que no sabe cómo estar a la moda, su estilo es equivocado.

Como se puede inferir a partir de los testimonios citados, la noción de autenticidad que es cuestionada cuando los entrevistados se refieren a los "ficticios", se constituye en una forma de modulación: el afán por diferenciarse se equipara al esfuerzo por articular la máscara con el individuo, esto es, por desplegar ante los ojos de los demás una imagen que corresponda a lo que los entrevistados denominan como "el modo de ser" de quien se exhibe. En este sentido, vale la pena subrayar una aparente contradicción: los entrevistados acostumbran a mencionar que poco les importa lo que digan los demás de su apariencia, sin embargo, apelan a diversos términos para referirse peyorativamente a aquellos en quienes es evidente el hecho de que no coincide su apariencia con sus pretensiones, como por ejemplo "gomelo de vereda", "ficticio", pero también (aunque de un modo distinto) el "ñero" o la "guisa". Si bien puede variar la preocupación por hacer de su apariencia una escenificación auténtica de lo que son, el rechazo a vestirse de un modo que traicione su modo de ser es unánime. En últimas, en algunos casos importará poco lo que digan los demás y, sin embargo, la observación constante sobre la apariencia propia y

11 A la hora de la verdad.

12 Parce, parcero, amigo. 
de otros es relevante para la articulación de las subjetividades de los jóvenes escolares.

Podría decirse que esta constatación es inoficiosa, pues qué elementos nuevos trae el hecho de que la gente se preocupe por cómo se ve. El punto que se quiere destacar es que esta preocupación no se refiere al simple cumplimiento de normas sociales establecidas, sino que se articula a dinámicas de poder que demandan de los individuos la construcción de una estética de sí: como lo ha sugerido Lipovetsky (2009), la moda implica la aspiración moderna de que los individuos se autoconstruyan, construcción que, como hemos planteado, supone la articulación compleja de la libertad y el poder. Así que la preocupación por la apariencia demanda de una lectura capaz de atender a las dinámicas de modulación en juego: ¿la preocupación por la apariencia y las claves culturales que se despliegan a través de sus conflictos (por las expectativas y por los atributos) actualizan, hacen presentes dinámicas sociales de dominación?

\section{El hábito que hace al monje: estética colectiva}

Como se ha dicho, el segundo tipo de conflictos se refiere a la adecuación entre tipologías y atributos, a la determinación de las características que "me definen", más aún a las tensiones que se articulan sobre lo que los demás esperan de cada uno. Aquí existe un campo complejo de innovaciones y tensiones claves que se relacionan con las subjetividades encarnadas, con las posibilidades del propio cuerpo y con cierta confrontación respecto a las tipologías mismas. Estos conflictos se desarrollan a partir, y a través de, la imperiosa tarea que la modernidad ha delegado a los sujetos: la de constituirse dándose sus propias reglas de legitimidad, tarea que se desarrolla en un escenario que, paradójicamente, se encuentra hiper-"controlado", esto es, modulado.

Paula Sibilia ofrece algunas pistas claves para abordar la pregunta planteada arriba. Vale la pena recordar que se ha dicho que la materia prima de cualquier forma de producción es la subjetividad encarnada. En este sentido, las apariencias se refieren a los modos como esa encarnación se desarrolla, dado que la máscara (forma de aparecer) es relacional.

Así como la subjetividad es necesariamente embodied, encarnada en un cuerpo; también es siempre embedded, embebida en una cultura intersubjetiva. Ciertas características biológicas trazan y deli- mitan el horizonte de posibilidades en la vida de cada individuo, pero es mucho lo que esas fuerzas dejan abierto e indeterminado. Y es innegable que nuestra experiencia también está modulada por la interacción con los otros y con el mundo. Por eso, resulta fundamental la influencia de la cultura sobre lo que se es. Y cuando ocurren cambios en esas posibilidades de interacción y en esas presiones culturales, el campo de la experiencia subjetiva también se altera, en un juego por demás complejo, múltiple y abierto. (Sibilia, 2009 p. 20)

La autora define la subjetividad como formas de ser y estar en el mundo. Dichas formas se han transformado a partir de las dinámicas propiciadas por la Internet, por las nuevas estrategias de narración que conducen a la constitución de un "yo" (narrado y reconocido por los demás como tal). Puede decirse en forma esquemática que ese yo se constituyó durante el siglo XIX y la primera mitad del XX, a través de las dinámicas de la introspección: diarios minuciosamente construidos, destinados a la intimidad, en la que los sujetos se entregan a la difícil tarea de dar cuenta de sí, de identificar aquello que les es más esencial. Se trata de subjetividades introdirigidas, que se nutren de novelas intrincadas, donde la "psicología" de los personajes se lee con la avidez de quien busca en la experiencia de otros, claridad sobre su propia realidad.

A partir de las complejas dinámicas de comunicación contemporáneas, la intimidad deviene en "extimidad", en una exhibición vía Internet de lo que ocurre al "interior" de la vivienda y de los sujetos. Si para las subjetividades introdirigidas, los muros de la habitación (arduamente conquistados) constituían un templo para el cultivo de su yo, las pantallas de los ordenadores se han convertido en las múltiples ventanas que conectan esa intimidad con la mirada de otros y que la van constituyendo en una exhibición, en un espectáculo. Por esta vía, los relatos autobiográficos se han ubicado como un importante nicho de mercado (novelas, películas, seriados, documentales), de modo que la gente se preocupa por las vidas ajenas, en un afán por encontrar en ellas los signos de la autenticidad que el consumo industrializado viene borrando. Y en este escenario, narrarse y exhibirse se hacen uno.

Como se ha venido planteando, los testimonios de los jóvenes abordados en los talleres ponen en el centro de sus experiencias, la cuestión del estilo, de una forma de presentarse que sea tanto llamativa como discreta, a la vez que aceptable para los demás y para uno mismo. La medida de la discreción y de la aceptabilidad es 
también la del estilo normal. Normalidad que se define en el terreno de la exhibición y que de este modo conecta con las tensiones planteadas por Sibilia respecto a la extimidad.

Ahora bien, conviene plantear que las dinámicas de exhibición se refieren también al desarrollo de diversas lógicas de negocio y de "explotación" de las capacidades humanas:

Pero los ejemplos son innumerables y de los más variados. Ese esquema que combina, por un lado, una convocatoria informal y espontánea a los usuarios para 'compartir' sus invenciones y, por el otro, las formalidades del pago en dinero por parte de las grandes empresas, parece ser 'el espíritu del negocio' en este nuevo régimen. La red social Facebook, por ejemplo, también decidió compensar monetariamente a quienes desarrollen recursos 'innovadores y sorprendentes' para incorporar al sistema. Por eso, diseñar pequeños programas y otras herramientas para ese sitio se transformó en una auspiciosa actividad económica, que incluso llegó a motivar la apertura de cursos específicos en institutos y universidades como la prestigiosa Stanford. (Sibilia, 2009p. 23)

En este sentido la subjetividad, la construcción de sí, se constituye no solo en la materia prima de la producción capitalista contemporánea, sino que se convierte en una importante mercancía. Este hecho recuerda la aguda percepción de Virno (2003) al referirse al capitalismo contemporáneo: ya no se trata solo de explotar las habilidades sociales, digamos su fuerza productiva, sino de aprovechar para el lucro las cualidades humanas específicas: la creatividad y la comunicación; esto es, aprovechar al ser humano mismo. Puede decirse entonces que la vida misma se convierte en fuerza productiva a la vez que mercancía.

Estos pocos ejemplos [referidos a jóvenes que exhibieron sus creaciones en Internet y fueron contratados por multinacionales] ilustran la forma en que opera el mercado cultural contemporáneo. Son sumamente arteros los dispositivos de poder que entran en juego, ávidos por capturar cualquier vestigio de 'creatividad exitosa' para transformarlo velozmente en mercancía. Para 'ponerla a trabajar al servicio de la acumulación de plusvalía', diría Suley Rolnik. Sin embargo, esa táctica suele ser ardientemente solicitada por los mismos jóvenes que generan dichas creaciones, tal vez sin comprender exactamente 'para qué se los usa', como intuyera Deleuze hace más de quince años, antes incluso de que la vetusta Web 1.0 llegara a popularizarse. (Siblia, 2009, p. 24)

Ese mostrarse demanda de los sujetos no solo cierta osadía, sino que implica, desde nuestra perspectiva, esa ética-estética de la autenticidad que el problema del estilo pone sobre el tapete. Se trataría, entonces, de las lógicas que promueven el paso de las subjetividades introdirigidas a las alterdirigidas, tal y como lo propone Sibilia:

En este siglo XXI que está comenzando, en cambio, se convoca a las personalidades para que se muestren. La privatización de los espacios públicos es la otra cara de una creciente publicitación de lo privado, una sacudida capaz de hacer tambalear aquella diferenciación de ámbitos antes fundamental. En medio de los vertiginosos procesos de globalización de los mercados, en el seno de una sociedad altamente mediatizada, fascinada por la incitación a la visibilidad y por el imperio de las celebridades, se percibe un desplazamiento de aquella subjetividad 'interiorizada' hacia nuevas formas de autoconstrucción. En un esfuerzo por comprender estos fenómenos, algunos ensayistas aluden a la sociabilidad líquida o a la cultura somática de nuestro tiempo, donde aparece un tipo de yo más epidérmico y dúctil, que se exhibe en la superficie de la piel y de las pantallas.

Se habla también de personalidades alterdirigidas y no más introdirigidas, construcciones de sí orientadas hacia la mirada ajena o exteriorizadas, no más introspectivas o intimistas. E incluso se analizan las diversas bioidentidades, desdoblamientos de un tipo de subjetividad que se apuntala en los rasgos biológicos o en el aspecto físico de cada individuo. Por todo eso, ciertos usos de los blogs, fotologs, webcams y otras herramientas como MySpace y YouTube, serían estrategias que los sujetos contemporáneos ponen en acción para responder a estas nuevas demandas socioculturales, balizando nuevas formas de ser y estar en el mundo. (Sibilia, 2009, p. 28)

En este punto, la distinción inicial de conflictos relacionales e identitarios, de aquellos que se originan en las expectativas (y que derivan en las estigmatizaciones y sus motivos) y los que se originan en los atributos (y que responden al problema de la aceptación ante sí y ante otros), encuentra un lugar de vinculación: el estilo. La búsqueda de una forma de ser diferente responde, al parecer, a esta lógica de las personalidades alterdirigidas (dirigidas por la mirada de otros). 
En los testimonios citados, esta visibilidad es esencial en tanto responde a la lógica de la diferencia y de la autenticidad: no ser como otro, definirse, establecer un estilo propio. Sin embargo:

Entrevistador: ¿Cómo es tu estilo? Mujer, 16 años: Yo pienso que tengo un estilo. No me visto diferente, pero sí pienso diferente, no me gusta decir por qué. Me considero normal, soy la típica niña risueña, que no le gustan los niños serios, que de lo mismo re-serios, se ven amargados. Me gusta el color azul y el verde, son como la armonía y la esperanza. No me gusta el color negro, porque es como un símbolo de la nada, que no hay nada.

Los estilos no necesariamente son creaciones individuales que apelan a la originalidad ${ }^{13}$, de modo que se trata de estéticas compartidas, de emocionalidades relacionales. Cierto que los estilos se aglutinan en categorías y estereotipos, pero también es cierto que estos implican creaciones individuales. En este ir y venir entre categorizaciones y creaciones, la distinción individuo-persona a la que se aludió ya, adquiere interés: el individuo apela a diversas personas (máscaras) para expresarse, se inscribe en diversos órdenes estéticos y a partir de su participación en ellos, los anima, los re-crea, y si es el caso, los impugna para reinventarlos, reinventándose al mismo tiempo.

Tenemos dos lecturas que se tensionan entre sí. De un lado, la noción de la máscara, que opera bajo la lógica del velo, de mostrar y ocultar lo que conviene, velo que opera en el lazo social definido por las estéticas, por los modos de ser y sentir juntos. Desde esta lectura, los estereotipos y las estigmatizaciones serían propios de una nueva sociabilidad, de un modo emergente de definir el vínculo social. Del otro, tenemos la construcción de la personalidad de forma alterdirigida, que se conecta con una cierta lógica de producción contemporánea. Los estilos están en esta encrucijada, la de romper con las lógicas disciplinarias a través del juego de los velos (de no dejarse observar plenamente desde el panóptico) y la de participar en nuevas formas de exhibición-explotación:

13 Vale la pena recordar que hemos usado el término autenticidad para referir la coincidencia entre la "apariencia" y el "ser". Aquí se trata de otra cosa, de la originalidad de quienes construyen sus apariencias, esto es, de apariencias propias que no apelan a modas o a estereotipos previos. Debe decirse que ni la autenticidad ni la originalidad van necesariamente de la mano. Se puede ser original y no auténtico, o viceversa.
Entrevistador: ¿Y en el colegio se alcanzan a notar esos estilos, o es muy difícil por el uniforme?

Mujer No. 4, 15 años: Sí, se notan, por el cabello, por la forma de peinarse. Mujer No. 5, 15 años: En la forma como usan el uniforme, hay gente que utiliza la sudadera entubada, o que la utilizan normal. Hay quienes usan la falda cortica, o muy larga, o las medias arriba de la rodilla Entrevistador: ¿Si la falda es larga? Mujer No. 4, 15 años: Es una inocente. Mujer No. 5, 15 años: A los hombres les gustan las mostronas.

Entrevistador: ¿Si la falda es cortica? Mujer No. 4, 15 años: Es una mostrona.

Entrevistador: Los ñeros y las ñeras ¿cómo usan el uniforme?

Mujer No. 5, 15 años: La falda corta, las medias sobre la rodilla, usan jardinera, y el saco se lo colocan arriba, que se vea el peto de la jardinera, la parte de arriba, la sudadera mostrando el ombligo, el pantalón entubado.

Estas tensiones entre estilos, se introducen por las grietas de las dinámicas disciplinarias, lo que puede ser entendido como una forma de resistirse e incluso de zafarse de este tipo de poder.

Entrevistador: Entonces ¿el vestido refleja la forma de pensar de cada quién?

Mujer No. 6, 16 años: Pues no la forma de pensar, pero si la forma de ser. Entrevistador: Explícame eso.

Mujer No. 6, 16 años: Si una persona se viste muy reservada, quiere decir que es alejada de los demás, pero si se viste descomplicada, es más amigable. Su manera de vestir no muestra cómo piensa: yo me puedo vestir como un flogger, pero pensar como un metalero, por ejemplo.

El modo como la entrevistada alude a la forma de vestir, mencionando que esta refleja el modo de ser y no el de pensar, implica una distinción clave: sugiere que el pensar no se relaciona con el ser. Invita a pensar sobre la importancia de lo que podríamos denominar como "emocional" para definir-se y para establecer quiénes son los demás. Esta diferencia ¿hace eco de la sociedad del control, organizada por el mercadeo y desligada del contrato social racionalmente establecido? ¿Se trata de esa misma lógica que pretende hacer negocio de la creatividad personal, de su emocionalidad, de las características específicamente humanas? Pero la cuestión aún por definir, por saber, es si esas grietas en el orden disciplinario han sido reorganizadas en nuevas 
formas de control, de apropiación del cuerpo, que opera menos en la organización de sus fuerzas (elemento este que al parecer se da por descontado) que en la organización de su "ser".

\section{Referencias}

Butler, J. (2009). Dar cuenta de sí mismo. Violencia ética y responsabilidad. Buenos Aires: Amorrortu.

Deleuze, G. (2006).Post-scriptum sobre las sociedades de control. En: Conversaciones. Valencia: Pre-textos.

Deleuze, G. y Guattari, F. (2003). Rizoma. Valencia: Pretextos.

Esposito, R. (2006). Bíos. Biopolítica y filosofía. Buenos Aires: Amorrortu.

Feixa, C. (1999). De jóvenes, bandas y tribus. Antropología de la juventud. Barcelona: Ariel.

Foucault, M. (1991). El sujeto y el poder.Bogotá: Carpe Diem.

Foucault, M. (2006a). Seguridad, territorio y nación. México: Fondo de Cultura Económica.

Foucault, M. (2006b). La hermenéutica del sujeto. México: Fondo de Cultura Económica.

Foucault, M. (1977). Historia de la sexualidad. 1. La voluntad de saber. México: Siglo XXI.

Goffman, E. (2008). Estigma. La identidad deteriorada. Amorrortu: Buenos Aires.

Guattari, F. y Rolnik, S. (2006). Micropolítica. Cartografías del deseo. Madrid: Traficantes de sueños.

Lipovetsky, G. (2009). El imperio de lo efímero. La moda y su destino en las sociedades modernas. Barcelona: Anagrama.

Maffesoli, M. (2007). El crisol de las apariencias. Para una ética de la estética. Madrid: Siglo XXI.

Sánchez-Criado, T. (2008). ¿Cómo y con quién hablan los cuerpos? Cuerpos en acción desde un punto de vista co-constructivista. En: M. Gil y J. Cáceres (Coords.), Cuerpos que hablan. Géneros, identidades y representaciones sociales. Madrid: Montesinos.

Sibilia, P. (2009) La intimidad como espectáculo. Buenos Aires: Siglo XXI.

Sibilia, P. (2009a). El hombre postorgánico. Cuerpo, subje-

72 tividad y tecnologías digitales. Buenos Aires: Siglo XXI. arte de embellecer desde el renacimiento hasta nuestros días. Buenos Aires: Nueva Visión.

Virno, P. (2003). Gramática de la multitud. Buenos Aires: Colihue. 